In the article "Participatory culture: citizenship-building process in Brazil", DOI number: 10.1590/1807-57622015.0941, published in the journal, Interface - Comunicação, Saúde, Educação, 2017; 21(63):907-20, at page: 907 :

Where it reads:

(c) Pós-doutorando, Fundação para a Ciência e a Tecnologia de Portugal. Lisboa, Portugal. mauroserapioni@ces.uc.pt

\title{
Reads up:
}

(c) Pós-doutorando, Fundação para a Ciência e a Tecnologia de Portugal. Investigador, Centro de Estudos Sociais, Universidade de Coimbra. Coimbra, Portugal. mauroserapioni@ces.uc.pt 